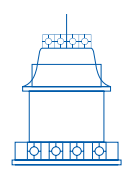

ARTÍCULOS

DE INVESTIGACIÓN

\title{
Los imaginarios de la revolución social. Acción colectiva y representación*
}

\author{
Carlos Alfonso Garduño Comparán \\ Facultad de Humanidades, Universidad Autónoma del Estado de México, Toluca, México \\ Email: eidoshumanidades1@gmail.com
}

Recibido: 2 de noviembre de 2019 | Aprobado: 3 de marzo de 2020

https://doi.org/10.17533/udea.ef.n62a07

Resumen: En este texto se desarrolla un acercamiento al problema de las formas de acción colectiva y de representación que se pueden presentar como alternativas con potencial de transformación de las condiciones sociales más allá de la estructura ideológica del sistema capitalista. A partir de una confrontación entre Cornelius Castoriadis y Slavoj Žižek con respecto a la posibilidad de autoinstitución de la sociedad y la necesidad de vincular la multitud a una representación unitaria, se analizan los dilemas concretos de la lucha revolucionaria a través de las figuras de Lenin y Robespierre. Este análisis permite concluir que la irrupción de la libertad de los colectivos en los eventos revolucionarios implica un tipo de violencia que impide determinar con certeza su dirección. Sin embargo, tal violencia también es la condición que enmarca el acto revolucionario en una dimensión ética, como una decisión que posibilita la transformación del imaginario.

Palabras clave: Slavoj Žižek, revolución, imaginario, representación, acción colectiva, autoinstitución, violencia

* Este texto forma parte de los trabajos del grupo académico "Estudios Transdisciplinarios sobre Cultura en América Latina" de la Facultad de Humanidades de la Universidad Autónoma del Estado del México.

\section{Cómo citar este artículo:}

Garduño Comparán, C. A. (2020). Los imaginarios de la revolución social. Acción colectiva y representación. Estudios de Filosofía, 62, 119-141. https://doi.org/10.17533/udea.ef.n62a07

\section{OPEN ACCESS}

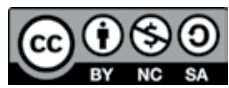

Estud.filos n. ${ }^{0}$ 62. Julio-diciembre de 2020 | pp. 119-141 | Universidad de Antioquia | ISSN 0121-3628 | ISSN-e 2256-358X 


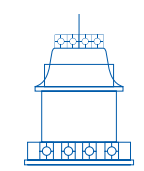

ARTÍCULOS

DE INVESTIGACIÓN

\title{
The imaginary of the social revolution. Collective action and representation
}

\begin{abstract}
This text develops an approach to the problem of the forms of collective action and representation that can be proposed as alternatives with potential to transform social conditions beyond the ideological structure of the capitalist system. The concrete dilemmas of the revolutionary struggle are analyzed through the figures of Lenin and Robespierre, after a discussion of the arguments of Cornelius Castoriadis and Slavoj Žižek on the possibility of self-institution of society and the need to link its multiplicity to a unitary representation. The paper concludes that the irruption of the collectives' freedom in revolutionary events implies a type of violence whose direction is difficult to determine with certainty. However, this violence frames the revolutionary act in an ethical dimension, as a decision that enables the transformation of the imaginary.
\end{abstract}

Keywords: Slavoj Žižek, revolution, imaginary, representation, collective action, selfinstitution, violence

\section{Carlos Alfonso Garduño Comparán}

Doctor en Filosofía por la Universidad Complutense de Madrid. Investigador posdoctoral apoyado por el CONACYT/ México en la Escuela Altos Estudios en Ciencias Sociales de París, Fonds Ricoeur y Hannah Arendt Center for Politics and Humanities. Miembro del Sistema Nacional de Investigadores del CONACYT desde 2016. Colaborador en el grupo de investigación "Estudios Transdisciplinarios sobre Cultura en América Latina" de la UAEMex. 


\section{Introducción}

Fredric Jameson (1991), en su crítica a la posmodernidad como lógica del capitalismo tardío, establece que, en nuestra época, para determinar los criterios de la acción colectiva frente a la dinámica cultural impuesta por el capitalismo y sus medios de reproducción de representaciones, se nos impone la necesidad de representar el espacio mundial del capital a modo de un mapa cognitivo. En principio, tal "representación de representaciones" debería ayudarnos a fundamentar nuestra práctica política, en el sentido de dotarnos de una herramienta para tomar decisiones en la lucha por transformar las condiciones de la vida social.

La cuestión, sin embargo, es a qué dilemas políticos nos lleva la elaboración de tal esquema cognitivo, al intentar transcender los límites impuestos por el imaginario capitalista. ¿Qué formas de acción colectiva y de representación se presentan como posibilidades de transformación más allá de la estructura ideológica que mantiene funcionando el actual sistema económico-político? ¿Cuáles son los problemas de representación a los que nos enfrentamos al tratar de concebir formas de organización social fuera de los límites del imaginario capitalista?

En este texto se propone un desarrollo de estas cuestiones tomando como eje rector el pensamiento de Slavoj Žižek. Para ello, se comenzará con un planteamiento abstracto de la cuestión del imaginario revolucionario, a partir de una confrontación entre Cornelius Castoriadis y Žižek, en relación a la posibilidad de autoinstitución de la sociedad desde su multiplicidad y la necesidad de vincular a la multitud a una representación unitaria que le dé consistencia. Posteriormente, se llevará la problemática a la discusión de los dilemas concretos de la lucha revolucionaria a través de las figuras de Lenin y Robespierre, lo cual nos permitirá concluir acerca de la irrupción de la libertad de los colectivos en los eventos revolucionarios, la violencia emancipadora y la totalitaria, y la fundamentación ética del acto revolucionario que posibilitaría en principio la transformación radical del imaginario en el que planteamos nuestras aspiraciones.

En último término, sin embargo, quizá la pregunta que más me inquieta, es la que plantea Castoriadis (1991) en relación al desarrollo de la civilización occidental: "¿Le ofrece Occidente actual (al tercer mundo), aparte de la abundancia de gadgets, algo con qué sacudirlo en su institución imaginaria? ¿Se le puede decir que el jogging y Madona son más importantes que el Corán?" (p. 24). A mi parecer, justo el problema del imaginario capitalista es que no puede ofrecer una respuesta satisfactoria. Lo cual, por otro lado, no significa que sólo quede como alternativa regresar al Corán, la Biblia o el Popol Vuh. En este sentido, este texto es un intento de pensar qué alternativa moderna tiene Occidente más allá de las ofertas del actual mercado mundial.'

1 Al respecto, vale la pena seguir la reflexión de Ponce (2020) acerca de la consigna "socialismo o barbarie", en distinto pensadores, desde Rosa Luxembrugo hasta Castoriadis. 


\section{Castoriadis con Žižek, 0 el dilema de los imaginarios de la autoinstitución y la representación}

En una entrevista acerca del sentido de la revolución, Cornelius Castoriadis (1991) destaca la especificidad de la Revolución francesa como la primera que plantea con claridad la idea de una autoinstitución explícita de la sociedad. Esta pretensión es lo que para Castoriadis define el sentido de una auténtica revolución.

Antes de la Revolución francesa, incluso en la inglesa o la americana, había revueltas, reformas, golpes de Estado o reinstituciones, frecuentemente basados en la tradición de un orden social cuyas bases fundamentales se intentaban conservar bajo principios que trascienden el ámbito social, ya sean religiosos o teóricos, como el del estado de naturaleza. Según Castoriadis, la novedad de la Revolución francesa es que la sociedad misma se lanzó a la empresa de autoinstituirse. ¿Con qué fin? No sólo por bienestar, felicidad o utilidad, ni siquiera por justicia, sino por libertad. Para Castoriadis, pues, la libertad es el principio fundamental de cualquier transformación auténticamente revolucionaria, relacionada por definición con la autonomía del colectivo que no sólo es un sujeto de cambio, sino el objeto de ese cambio. ${ }^{2}$ La libertad está directamente vinculada al ideal colectivo de constituirse a sí mismo bajo una ley dada por él mismo. ${ }^{3}$

Según Castoriadis (1991), quienes descubrieron que "toda institución de la sociedad es autoinstitución" (p. 8), fueron los griegos, pues desde las reformas de Solón hasta la revolución de Clístenes - que pusieron las bases de la democracia ateniense-generaron gradualmente la consciencia de que esa institución compete al nomos y no a la physis. ${ }^{4}$ Sin embargo, a pesar de sus logros, esa democracia no tocó las estructuras sociales y económicas recibidas, dejando intactas al interior del oikos las desigualdades de género y de clase, bajo la justificación de principios naturales. Algo análogo, piensa Castoriadis, sucedió con la Revolución americana, donde se establece una declaración que traduce los "derechos naturales" para la base social de pequeños productores independientes, lo cual como en Grecia, mantiene intacta una estructura de desigualdades sociales, permitiendo la esclavitud, segregación y diversas formas de discriminación.

La revolución radical, pues, debería cuestionar, "en derecho, la totalidad de la institución existente de la sociedad" (Castoriadis, 1991, p. 9), lo cual nos lleva a un difícil problema teórico-práctico: "La Revolución francesa no puede crear políticamente si no destruye socialmente" (Castoriadis, 1991, p. 9). ¿Puede haber una auténtica democracia si no se atacan de raíz las estructuras que reproducen las desigualdades económicas y sociales? ¿No es lo social y lo económico, por ello, directamente político? ¿Cómo, sin

2 Para profundizar en la noción de autonomía de Castoriadis en relación al sujeto revolucionario, consúltese (Rosso, 2020).

3 Para una exploración detallada del potencial creativo del imaginario según Castoriadis, en contraposición con su apropiación por parte del capitalismo, consúltese Telios (2019).

4 Para profundizar en el interés de varios pensadores franceses contemporáneos, entre ellos Castoriadis, por la democracia antigua, consúltese Moreno Pestaña (2018). 
embargo, destruir, y al mismo tiempo instituir, sin llevar a la sociedad a una crisis que impida la realización de sus objetivos, y que, probablemente, termine en una situación política de mayor represión y una situación económica insostenible?

En específico, es pertinente retomar una de las preguntas del entrevistador: “¿Puede una generación hacer un boquete en la historia operando en la discontinuidad pura?" (Castoriadis, 1991, p. 10). A lo que Castoriadis responde que uno tendría que plantearse el problema de la relación entre libertad y razón: "Cuando digo que la historia es creación ex nihilo, esto no significa en modo alguno que ella sea creación in nihilo ni cum nihilo" (Castoriadis, 1991, p. 10). Nunca, piensa Castoriadis, hay rompimiento total o discontinuidad pura, sino que "la ruptura está en el sentido nuevo que ella confiere a lo que hereda o utiliza" (Castoriadis, 1991, p. 11). Con ello, no se trata de que la razón de manera pura imponga un nuevo sistema al que se deba hacer entrar a la sociedad, en una especie de rousseaunismo perverso en el que "se les forzará a ser racionales" (Castoriadis, 1991, p. 11). En ese punto, la pretendida libertad de la razón se vuelve terror e, inevitablemente, lleva a que la supuesta soberanía del pueblo sea reemplazada "por la Razón de sus 'representantes', en nombre de la cual será atropellada, forzada, violada, mutilada" (Castoriadis, 1991, p. 11).

El problema, entonces, es cómo lograr, después de la ruptura revolucionaria, que el pueblo no se retire de la escena -dejando toda la transformación en manos de un Estado o partido que terminará monopolizando las decisiones e imponiéndolas por la fuerza-. ¿Cómo, pues, lograr mantener una "mediación viviente", para evitar que quede de un lado la "entidad abstracta de la 'Nación', del otro los que la 'representan' (...), y, entre ambos, nada"? (Castoriadis, 1991, p. 12). El tema, entonces, es cómo es posible, si lo es, el "autogobierno de todas las formaciones colectivas intermedias" (Castoriadis, 1991, p. 12).

Su misma línea de argumentación lleva a Castoriadis a rechazar la idea del Estado como lugar desde donde se ha de ejercer el poder, suponiendo que este se puede ejercer efectivamente desde el colectivo revolucionario. Y, en consecuencia, a plantearse la superación del imaginario del Estado-Nación, en el que el poder sólo puede ejercerse a través de la entidad representativa del Estado.

Al respecto, es pertinente retomar su lectura de la Revolución rusa. Para Castoriadis (1991, pp. 14-15), la auténtica revolución tuvo lugar desde 1905 donde la acción era coordinada por la forma de autoorganización colectiva del soviet, que se prolonga hasta 1921 con los comités de fábricas. En cambio, a su juicio, el fracaso de la revolución se da en octubre de 1917, donde Castoriadis ve un putsch, un golpe de Estado militar, que llevará a romper con la voluntad popular y a imponer la lógica del Partido Bolchevique.

Ahora bien, ¿puede haber auténticamente revolución sin una ruptura violenta que implique una alteración de la legalidad establecida? "Seguramente no", afirma Castoriadis (1991, p. 16); pero todo el asunto consiste en determinar en qué debe consistir esta violencia para salvar el sentido emancipador de la revolución y evitar su degeneración totalitaria. 
De acuerdo con lo que hemos visto, entonces, Castoriadis rechaza el terror como imposición de la racionalidad de un Estado o partido, ya sea que intente transformar la sociedad o frenar esa transformación. En contra, apoya la idea de una ruptura basada en el autogobierno de diversas formas de organización colectiva, en las que su acción vaya generando su propia legislación, como un proceso de autoinstitución. La autonomía de la razón se debería imponer sobre el dominio instrumental de la razón; el problema, así, es análogo al de la Dialéctica de la Ilustración (Adorno \& Horkheimer, 2002), donde más que cortar con el pasado para instaurar un sistema puramente racional, la revolución debería "instaurar otra relación con la tradición -no tratar de suprimirla" (Castoriadis, 1991, p. 17). Debería ser una cuestión de libertad y no de dominio: "la cuestión de una sociedad libre hecha de individuos libres" (Castoriadis, 1991, p. 18), que no sólo sean regidos por sus leyes, sino que participen en su formación y en el ejercicio del poder, combatiendo, en consecuencia, la apatía, la despolitización y el dominio de los medios de comunicación. Es, en suma, la cuestión de cómo fomentar una sociedad en la que reinen las pasiones por lo público y no por lo privado. Una sociedad de ciudadanos y no de consumidores o usuarios de un sistema, como parece terminar imponiendo el imaginario capitalista actual.

Ahora bien, para Slavoj Žižek (2006), este planteamiento de la cuestión resulta muy problemático. En un alegato en pro de una Revolución Cultural como la que propuso Mao Zedong, como respuesta a los desarrollos teóricos de Gilles Deleuze y Felix Guattari, en los que se pone el acento en la acción de la multitud contra el predominio de la representación y la trascendencia de organismos políticos como el Estado o los partidos, Žižek destaca el siguiente problema:

no es posible limitarse a oponer sencillamente la multitud inmanente subversiva al poder trascendente de un Estado centralizado: fue el propio establecimiento de un poder estatal centralizado durante los siglos diecisiete y dieciocho lo que creó el espacio para la aparición en primer plano de la multitud política moderna (Žižek, 2006, pp. 224-225).

En contra, pues, de la interpretación de Castoriadis, lo que realmente revolucionó a la sociedad para Žižek, promoviendo su politización, fue el surgimiento de un nuevo Estado moderno y no la acción autónoma del pueblo.

Por ello, para Žižek, la verdadera cuestión no es cómo deshacerse del Estado o reducir al mínimo su representación, sino qué sería en realidad, más allá de asumir una resistencia, una multitud en el poder. ¿Puede una multitud efectivamente ejercer el poder? ¿O es propio del poder centralizarse y funcionar, en el mejor de los casos, de forma representativa?

Los ejemplos de Žižek son de especial interés aquí porque refieren a procesos revolucionarios latinoamericanos. Uno de ellos es el de Hugo Chávez en Venezuela. La lectura de Žižek es que, ahí, la "multitud en el poder" terminó actualizándose "en forma de un líder autoritario cuyo carisma puede servir de 'significante vacío' capaz de contener 
la multitud de intereses" (Žižek, 2006, p. 226). Como suele pasar en Latinoamérica, los procesos revolucionarios y movimientos sociales en general terminaron concentrándose en la figura de un caudillo, que a partir de entonces se convirtió en el responsable de la actividad y en el depositario de los anhelos colectivos, provocando en consecuencia una nueva concentración del poder y una polarización social más marcada que la que se pretendía superar.

Un caso teóricamente más interesante es el de la resistencia zapatista en Chiapas. Su objetivo, contrario al de la Revolución Bolivariana, no es asumir el control del gobierno con la aspiración de cambiar la sociedad en su totalidad, sino crear espacios autónomos en lugares marginales del edificio social, como son las comunidades indígenas campesinas. El punto de Žižek es que, incluso en estos casos en que se pretende, desde la multiplicidad, ejercer una resistencia que vaya transformando las condiciones sociales desde lo regional, se tiene que referir a un líder carismático como contenedor vacío. En este caso, el Subcomandante Marcos, como Chávez, cumple la función del Significante Amo, como elemento estructural que le brinda al colectivo su fuerza de totalización y homogeneización. El vacío que permite la consistencia y unidad del conjunto.

Dicho de otra manera, parece que la acción política, aún la más revolucionaria, requiere siempre de un elemento extra-social, análogo al Estado, como forma de representación, no de los intereses de la multitud, sino de la unidad del colectivo como principio de su estructura organizacional. O dicho de otra manera, ¿no es verdad que el pueblo no existe por sí mismo, sino sólo a partir de la imposición de un nuevo Significante Amo, como forma de representación que posibilita, de hecho, la existencia del pueblo? ¿Puede un pueblo darse a sí mismo una Ley, como si existiera previamente a ella? ¿O es precisamente la imposición de la Ley la que le da su forma al pueblo? Y más aún, ¿qué pasaría con la multitud si funcionara fuera de la ley? ¿Cómo podría demandar derechos y reivindicaciones si no hubiera un Estado que atendiera la demanda? ¿No es verdad que en la ilegalidad, la multitud más bien estaría vulnerable y caería en dinámicas viciosas como el narcotráfico, la trata de personas o la dominación del más fuerte?

El problema, entonces, después de haber repasado los argumentos de Žižek y Castoriadis, puede plantearse en los siguientes términos: existe una aspiración sociopolítica legítima en función de la cual se emprenden procesos revolucionarios, cuyo objetivo, si se asumen radicalmente, es la autoinstitución de la sociedad, bajo un principio de libertad y racionalidad, es decir, de autonomía. Tal objetivo ha sido constantemente traicionado por la irrupción de una entidad representativa que termina por quitarle el poder a los actores sociales y concentrándolo en ella, en una tendencia a separarse de la sociedad hasta convertirse en un aparato de dominación. Por otro lado, ¿no es cierto que esa entidad representativa posibilita la aspiración de una autoinstitución, dándole una estructura unitaria y homogénea al colectivo y sus anhelos para que puedan expresar sus demandas? Además, ¿no es verdad que sin esa estructura de representación el colectivo está en riesgo de dispersarse en una 
multitud vulnerable? ¿Que sin el apoyo estructural de un líder, un Estado o un partido, la multitud pierde el poder?

La cuestión, en suma, sería: ¿cómo lidiar con los imaginarios de la ruptura revolucionaria que posibilitan la transformación social radical bajo un anhelo de libertad y un principio de autonomía, y de aquel de la figura de un representante que, como estructura significante, concentra los anhelos y demandas, posibilitando la cohesión del colectivo y su poder de acción en conjunto?

\section{Lenin. Organización más allá del capital}

Tras analizar los argumentos de Castoriadis y Žižek, podemos plantear que uno de los dilemas fundamentales de la transformación social concierne al imaginario en función del cual es efectivamente posible. Y, sin embargo, esta discusión permanecerá como una especulación si no atacamos el problema de cómo enfrentar las condiciones políticas, sociales, culturales y económicas generadas por el desarrollo del capitalismo.

Por supuesto, siguiendo a Castoriadis, tendría que haber una ruptura respecto a los modos de organización capitalistas que favoreciera la autonomía de los colectivos. Y siguiendo a Žižek, tendríamos además que encontrar las formas de representación para darle consistencia a esas empresas colectivas, de manera que puedan sostenerse frente al capitalismo y más allá de su orden.

El problema, históricamente, coincide con la Revolución rusa, en el sentido de que fue la primera emprendida en un contexto dominado por la industria, que intentó consolidar una alternativa, no sólo proponiendo nuevas formas de organización social, sino un nuevo tipo de Estado. En nuestro momento histórico resulta claro que dicho intento fracasó. Pero justo por ello es importante retomarlo, para comprender cómo podríamos repetir la empresa, basados en sus legítimas aspiraciones.

El análisis de la figura de Lenin es aquí fundamental. Su relevancia para la reflexión filosófica tiene que ver, más allá de las consecuencias de sus decisiones, con la íntima relación entre su praxis y su comprensión teórica de los acontecimientos. No porque Lenin simplemente estuviera siguiendo una teoría, sino porque las exigencias de la práctica, en las complejas circunstancias históricas del proceso revolucionario, lo llevaron a cuestionar los principales problemas de la filosofía política para hacerle justicia al espíritu de la revolución.

Según Georg Lukács, el rasgo fundamental de Lenin es la coherencia de su pensamiento, tras haber asumido el rol de pensador proletario. En cuanto tal, es decir, en cuanto individuo que asumió políticamente el destino de su clase, comprendió que "toda verdad abstracta se convierte en palabrerío cuando se aplica a una situación concreta cualquiera" (Cita de Lenin en Lukács, 2005, p. 109). Su rol no se reducía a proclamar la necesidad de un cambio, como si fuera el representante de una idea válida por sí misma. Es proverbial el carácter sobrio de Lenin en contraste con la voluptuosidad de 
la oratoria de Trostky. Lo cual, piensa Lukács, se debe sobre todo a que la idea básica de Lenin no es que necesitamos una revolución, sino que ella siempre es actual -tal como supone Castoriadis.

En otras palabras, si Lukács tiene razón, Lenin era consciente de que una revolución no se planea y no es la consecuencia de un programa o un conjunto de ideas previamente establecidas, sino que acontece en el momento en que las condiciones del desarrollo histórico de las sociedades lo posibilita. En virtud de ello, comprendió que la labor de un verdadero líder no consiste en movilizar al pueblo, sino en permitirle ver las tendencias orientadoras que posibilitan el cambio, detrás de las ideologías que determinan la conciencia cotidiana. En este sentido, Lenin mostró que la actividad política del proletario debe determinarse por el objetivo de su emancipación, y que ésta, a su vez, es posible sólo en virtud de una interpretación realista de su situación y de una estrategia adecuada.

Por ello, señala Lukács (2005), para transformar el mundo, Lenin supo antes cómo interpretarlo. Es decir, pudo ver en el microcosmos de su situación concreta el macrocosmos de la tendencia de una época (p. 33); la dinámica capitalista en su conjunto y su crisis, que no sólo percibió, como cualquier otro individuo, en la miseria indignante, sino en sus posibilidades revolucionarias. "Lenin fue el único que dio el paso para hacer concreto un marxismo, a partir de ahora, absolutamente práctico" (Lukács, 2005, p. 36), al ayudar al proletario ruso a encontrar su propia conciencia y mostrarle que esta depende del hecho de organizarse para realizar la transformación social, la cual no requiere ser anunciada y prometida, sino llevarse a cabo de acuerdo a la dirección, no de Lenin y sus ideas, sino de las circunstancias concretas.

Con esto, Lenin rompe con cualquier fatalismo y se convierte en el intérprete de los signos de la revolución inminente, que básicamente giran en torno al hecho de que "las capas sociales inferiores' no quieren seguir viviendo como antes y que 'las capas sociales superiores' no pueden seguir viviendo como antes" (Lukács, 2005, p. 50). Es decir, Lenin entiende que la dialéctica no es un conjunto de preceptos que deben regir la acción, sino referencias para interpretar las contradicciones sociales y comprender que en momentos determinados de la historia es posible producir algo nuevo como forma de organización que no sólo suprima lo anterior, sino que lo perfeccione, adaptándolo a las necesidades de la clase obrera.

¿Quiere decir esto que Lenin fue una especie de hermeneuta? Aunque el filósofo Paul Ricoeur (1986) sugiere esa caracterización, ${ }^{5}$ el estudioso militante Louis Althusser se apresura a desmentirlo. La interpretación leninista no parte de desarrollos hermenéuticos, porque estos, como la filosofía tradicional en general, no son más que "el camino de los caminos que no conducen a ninguna parte" (Althusser, 2008, p. 119). ${ }^{6}$ La tendencia fundamentalmente

5 En sus Conferencias sobre la ideología y la utopía, en las secciones dedicadas a discutir con Louis Althusser.

6 La frase es una cita de Joseph Dietzgen: "den Holzweg der Holzwege". 
práctica y transformadora del pensamiento de Lenin, que refleja el espíritu de la Tesis XI sobre Feuerbach de Marx, ${ }^{7}$ contrasta, según Althusser, con el carácter más bien especulativo de la hermenéutica. Si algo no hace Lenin, piensa Althusser, es buscar el sentido de los signos históricos; él más bien los interpreta para organizarse con miras a la transformación de las condiciones sociales. En consecuencia, según Althusser, más que a una hermenéutica, Lenin recurre a una ciencia, el materialismo histórico, ya que su filosofía es una actividad que se realiza fuera del ámbito teórico, en el campo de la praxis política.

Aunque tal distinción deja claro que la filosofía no es una ciencia, a su vez demuestra que existe un vínculo privilegiado entre la filosofía y las ciencias (Althusser, 2008, p. 133), pues estas ofrecen los elementos teóricos y objetivos para que la primera se pueda desarrollar en su esencia, tal como la entiende el marxismo, es decir, en la práctica y no en la especulación que no lleva a ningún lado.

Ahora bien, si entendemos dialécticamente tal relación entre ciencia y filosofía, hemos de reconocer que no se trata sólo de que la praxis política en la que se realiza la filosofía marxista siga la dirección del análisis científico de las condiciones objetivas del desarrollo histórico, sino que la filosofía intervenga en el dominio teórico de la ciencia. Citando a Althusser (2008, p. 140), "esta función consiste en 'trazar una línea de demarcación' en el interior del domino teórico entre las ideas declaradas verdaderas y las ideas declaradas falsas, entre lo científico y la ideología”. De esta manera podemos entender que la aportación de Lenin a la filosofía consiste en mostrar no sólo que su esencia debe ser la práctica con consecuencias emancipadoras, sino que ésta debe a su vez ser capaz de establecer la diferencia, en un contexto determinado, entre el uso de las ideas con una intención exclusivamente ideológica de aquel con intención práctica.

Ahora bien, una vez señalado que lo propio del pensamiento leninista consiste en concebir la filosofía como praxis que, haciendo uso de las ciencias es capaz de determinar el rumbo de su acción distinguiendo entre usos de ideas, cabe preguntarse sobre la esencia de su acto, con el fin de determinar su autenticidad. Ciertamente, a Lenin suele relacionársele, como hace Castoriadis, con la idea del partido como forma privilegiada de organización, pero ¿eso agota el leninismo?

Según Žižek (2004), lo que Lenin identificó durante la Primera guerra fue la desaparición de un mundo entero (p. 8), caracterizada por la pérdida de fe en el progreso. Ante este desastre, se encontraba en una situación desesperada, lo cual, sin embargo, posibilitó el acontecimiento revolucionario: "ESTA catástrofe abrió el escenario para el acontecimiento leninista, para romper el historicismo evolutivo de la Segunda Internacional, y sólo Lenin estuvo a la altura de esta apertura, sólo él articuló la Verdad de la catástrofe" (Žižek, 2004, p. 8).

7 "Los filósofos se han limitado a interpretar el mundo de distintos modos; de lo que se trata es de transformarlo" (Marx, 1974, p. 668). 
Lo revolucionario en Lenin implica dos elementos: la identificación de una oportunidad única para la revolución y el replanteamiento de las relaciones entre teoría y práctica, superando los puntos de vista dominantes en el horizonte político anterior con fundamentos que responden al momento histórico. Por ello, para Žižek (2004), "su libro El Estado y la revolución es el correlato estricto de esta experiencia devastadora de 1914" (p. 8). En su implicación subjetiva con las condiciones de existencia prevalecientes, Lenin logró plantear con claridad los fundamentos de un proyecto de emancipación que no podía aplazarse. No se trataba de una utopía ni de una idealización, sino de un impulso: "Este impulso del momento es la verdadera utopía. Con lo que habría que quedarse es con la locura (en sentido kierkegaardiano estricto) de esta utopía leninista, mientras que el estalinismo representa, si acaso, un retorno del 'sentido común' realista" (Žižek, 2004, p. 9). ${ }^{8}$

Žižek opone así a Lenin y a Stalin, tomando partido por el primero, con el fin de recuperar la esencia de su impulso. Stalin representa agotamiento y olvido, el fracaso revolucionario y su degeneración totalitaria, en el mismo sentido en que Walter Benjamin indica que "cada ascenso del fascismo da testimonio de una revolución fallida" (Žižek, 2013, p. 24). Lo propiamente revolucionario, por tanto, no tiene que ver con la implementación de un plan de desarrollo social desde el Estado, como en el caso de Stalin, sino con la identificación de las posibilidades de transformación en ciertas circunstancias. En específico, lo que Lenin identificó fue la ambigüedad de la democracia tras el derrocamiento del Zar y el potencial de los soviets, "lo que uno se siente tentado a llamar micropolítica revolucionaria" (Žižek, 2004, p. 10), como sustituto de la nomenklatura de partido. Lenin descubrió que los viejos mecanismos democráticos habían perdido eficacia y que los ideales de libertad y justicia podían ser mejor representados por otras formas de organización, a las que acudió en busca de apoyo.

En este sentido, la revolución puede entenderse como la superación de la forma de organización predominante, renunciando a las viejas referencias. Lo que caracteriza una revolución es, precisamente, el atrevimiento para actuar más allá ellas: "se debería asumir el ACTO revolucionario sin la cobertura del gran Otro: el miedo a tomar el poder 'prematuramente', la búsqueda de garantías, es el miedo al abismo del acto" (Žižek, 2004, p. 11). No existen, desde esta perspectiva, condiciones objetivas para la revolución, y quienes pretendan determinarlas a través de una teoría, como hacía notar Rosa Luxemburgo, esperarán por siempre. ${ }^{9}$

8 El acto revolucionario como un momento de locura kierkegaardiana es una noción fundamental en la comprensión de la implicación subjetiva. Como veremos, tal noción depende de un tipo de materialismo específico y de una verdad que exige fe del individuo, por lo que Žižek la referirá al cristianismo, particularmente a su negación momentánea de la identidad personal, sin renunciar al mundo en pos de un sentido trascedente (Wennerscheid, 2014).

9 En este sentido, es pertinente calificar el acto revolucionario como un "acto fantasmal" que no está determinado por las condiciones, sino que permite incidir sobre ellas (Álvarez, 2013). 
La cuestión que se presenta aquí es la de cómo identificar la oportunidad revolucionaria sin una referencia objetiva. Lo que Žižek (2004) supone es que, ante la opacidad y la carencia de "verdaderas opciones" (p. 15), lo que una teoría política revolucionaria se plantea, parafraseando a Benjamin, ${ }^{10}$ es "cómo funciona efectivamente en estas propias luchas (sociales)" (Žižek, 2004, p. 15). Tal eficacia en las luchas implica una noción de verdad que no se basa en elementos objetivos, sino en compromisos asumidos con una causa políticosocial: "La verdad UNIVERSAL de una situación concreta sólo se puede articular desde una postura por completo PARTIDISTA: la verdad es por definición unilateral" (Žižek, 2004, p. 22). Así, lo que una teoría exige, no es la aclaración de las condiciones objetivas que la posibiliten, sino un sujeto implicado que posibilite la transformación de tales condiciones.

Pero, ¿no era Lenin un materialista? Žižek critica la postura asumida por Lenin en Materialismo y empiriocriticismo y propone que lo verdaderamente revolucionario de su acontecimiento radica en "la idea 'materialista' judeocristiana de que la verdad sólo puede aparecer a partir de un encuentro traumático EXTERIOR que hace pedazos el equilibrio del sujeto" (Žižek, 2004, p. 26). ${ }^{1 "}$ La verdad que Žižek refiere, entonces, no está dada en un mundo, en la sociedad o en alguna totalidad que podamos representar y estudiar de manera objetiva, sino en algún lugar indeterminado, exterior al sujeto, quien sólo cobra conciencia de ella cuando altera su orden interior en eventos como la Revolución de 1917. Lo que la verdad afecta, por tanto, no son condiciones objetivas, sino la posición del sujeto; lo que importa no es que éste conozca científicamente, sino que ocupe el lugar de la verdad, que hable y actúe desde ella. Tal sería, en consecuencia, la base de la legitimidad del partido, como forma de representación: la adecuada conciencia de clase en una situación social específica (Žižek, 2004, p. 30).

En este sentido, el problema del nazismo, que le impidió ser un auténtico movimiento revolucionario, fue que no reconoció la verdad del lugar que debía asumir el partido en su contexto, sustituyendo la lucha de clases por la lucha racial (Žižek, 2004, p. 33). No reconoció lo real del antagonismo que exigía tomar postura y transformar las condiciones sociales, sino que lo sustituyó por su fantasía. En cambio, Lenin identificó el antagonismo de la lucha de clases en Rusia, lo cual le permitió formalizar a Marx (Žižek, 2004, p. 34) y actualizar la verdad de su teoría. ${ }^{12}$

En un gesto provocador, Žižek asegura que, mientras el nazismo no contaba con ninguna verdad interna, como llegó a afirmar Martin Heidegger (2001, p. 179), el

10 En El autor como productor, Benjamin (2004) argumenta que lo que ha de juzgarse de una obra de arte es su función en las relaciones sociales, y no meramente sus cualidades objetivas, siendo una obra de calidad la que contribuye a transformarlas.

11 Para profundizar en tales nociones de materialismo y verdad consúltese La política de la verdad, o Alain Badiou como lector de San Pablo (Žižek, 2001). Lo cual, por supuesto, debería llevar a la lectura de los textos fundamentales de Badiou (2003; 2008; 2018) acerca de la verdad, el ser y el acontecimiento. Por otro lado, para profundizar sobre el constante diálogo entre Žižek, Badiou y otros de sus colegas sobre la idea del comunismo, consúltese Badiou et al (2010). Igualmente, para profundizar en la participación de Žižek en el proyecto de rehabilitar la política de la verdad, consúltese Hernández Vergara (2018).

12 La noción de antagonismo es fundamental en la comprensión de Žižek de lo político. Al respecto, consúltese Camargo (2013), donde se argumenta la necesidad de tal noción para ampliar los límites de la reflexión. 
bolchevismo sí la tuvo y radicaba precisamente en el acontecimiento leninista (Žižek, 2004, p. 35). La cuestión, entonces, es ¿por qué, a pesar de su verdad, la Revolución rusa degeneró en un sistema totalitario? Žižek se esfuerza en mostrar que la diferencia entre un acto revolucionario y un régimen totalitario no radica en la ausencia o uso de violencia, sino en que en ambos se dan distintos tipos de violencia: la del primero redentora y la del segundo opresora.

¿Qué es la violencia redentora? La destrucción de la forma de identidad predominante en cierta sociedad. Según Žižek, la Revolución de Octubre fue una auténtica expresión de violencia redentora y no un simple golpe de Estado. Esto lo podemos apreciar, a su parecer, en las representaciones escénicas del "Asalto al Palacio de invierno", en el tercer aniversario de la Revolución, o incluso en Octubre, de Sergei Eisenstein. Estas representaciones, más que ser meros procedimientos ordenados por el Estado, eran auténticas fiestas populares:

¿No muestra la representación del 'Asalto al Palacio de Invierno' la fuerza de una fiesta sagrada (profana), del acto mágico de fundar una nueva comunidad? Es aquí donde Heidegger debería haber mirado cuando escribió sobre la fundación de un Estado como el acontecimiento de verdad (y no en los rituales nazis) (Žižek, 2006, p. 231).

En contra, pues, de la estetización de la política ${ }^{13}$ que Benjamin le recriminaba al nazismo, las conmemoraciones y representaciones de la Revolución de Octubre parecen dar cuenta de un autentico acontecimiento emancipador en el que el pueblo se ve reflejado, haciéndose consciente de sí. ¿Pero qué es lo que el pueblo ve de sí, exactamente, en estas representaciones? La respuesta de Žižek es fundamental para comprender en qué sentido un acontecimiento puede llegar a ser emancipador con relación al sistema económico, pero también en qué sentido podría pervertirse. Lo que ven en la representación son sus excesos, a modo de gastos improductivos tal como los entiende Georges Bataille (1987).

Aquí, la cuestión fundamental radica en comprender en qué sentido este gasto improductivo no coincide con el consumismo promovido por el sistema capitalista. En su ensayo sobre la reproductibilidad técnica, Benjamin (2003) muestra cómo el arte, al volverse dependiente de las técnicas de reproducción, pierde el lugar que tradicionalmente lo vinculaba al culto y se desplaza, en nuestra época, al de la política. En tal horizonte, Benjamin identifica dos posibilidades de su desarrollo, la estetización de la política, característica del fascismo, y la politización del arte, característica del comunismo. Lo importante es que tales alternativas se relacionan con distintos tipos de violencia, cuya descripción podemos encontrar en el ensayo de Benjamin (2001) Para

13 Abordaremos esta noción a continuación, en relación a la noción de violencia mítica del mismo Benjamin y en oposición a la politización del arte propia del comunismo y la noción de violencia divina. 
una crítica de la violencia. La estetización de la política es la manera en que la llamada violencia mítica es ejercida con el fin de reforzar estructuras legales que intentan imponer un sistema de medios y fines que, en nuestro contexto, favorecen el desarrollo del capitalismo a través de sus múltiples estrategias mediáticas y publicitarias; mientras que la politización del arte es la expresión que da cuerpo a la violencia divina que pugna por disolver la estructura legal que nos mantiene atados a relaciones determinadas por el sistema económico.

Ambas posibles formas de representación y de violencia nos enfrentan a un dilema que puede enunciarse en los siguientes términos: o aceptamos ejercer el poder en el marco del sistema económico-legal, consumiendo lo que nos ofrece su reproducción en una lógica de medios-fines, o rechazamos el sistema negándonos a su goce, intentando ejercer el poder fuera de él, exponiéndonos a lo que Benjamin llama violencia divina.

La violencia divina tiende a disolver el orden definido por la ley y con ello el tejido social y político que se nos impone como una especie de destino. Es, además, redentora, sin derramar sangre. Y, finalmente, no exige sacrificios, sino que los acepta. Estamos, pues, frente a una lógica religiosa y sacrificial, que no puede entenderse en términos de una racionalidad calculadora como la que exige el capitalismo.

Al respecto, Judith Butler (2006, p. 204) destaca que, aunque en la violencia divina ya no funcionamos en el orden de los sistemas económico-legales, sigue habiendo cierta exigencia moral que actúa como guía, como cuando Benjamin (2001) refiere al mandato "no matarás" (p. 42). Es decir, el hombre sigue siendo responsable de su acción frente a Dios, pero su comportamiento ya no es controlado por motivos económicos o por un Estado. Su función consiste en quitar a los sistemas imperantes la facultad de ejercerla y otorgársela a los individuos, quienes a partir de este momento deben responsabilizarse absolutamente de ella. ¿Qué se logra con esto? Que la violencia pierda su justificación, enfrentando, por ello, a quienes han de ejercerla a la obligación de hacerse cargo por completo de las consecuencias. De ahí que, para Benjamin, esta violencia acepte el sacrificio en lugar de exigirlo.

A lo que se apunta es a la modificación de nuestra relación con la violencia. Por otro lado, no se trata de una violencia no-violenta, como pretenden caracterizarla Butler (2006) o Critchley (2009). Que no sea sanguinaria, en el sentido de que no exige sacrificios para seguir reproduciendo los fines de un sistema económico-legal, no implica que no tenga efectos o consecuencias dañinas sobre los sujetos. De ahí la preocupación de Žižek sobre lo que podría suceder en el estado de ilegalidad en el que el colectivo debe asumir su responsabilidad.

De tal forma, no se trata de una violencia que pueda ser planeada, calculada y ejecutada, sino de una que se le presenta al sujeto, enfrentándolo a la decisión de asumirla. Hablamos de una violencia ética, porque no está determinada por alguna reglamentación previa, sino que tiene su origen en la libertad del sujeto. Es, pues, una violencia soberana, por lo que no podría ser condenada en algún tribunal. 
Esta violencia implica la apertura de una oportunidad de subversión, la cual, sin embargo, corre el riesgo de no ser identificada, perdiéndose la capacidad de intervenir en ella. Cuando esto sucede, otros tipos de violencia irrumpen, como formaciones defensivas que tienen la función de "tapa[r] el vacío dejado por la incapacidad para intervenir de hecho en la crisis social" (Žižek, 2004, p. 72). Así, estas manifestaciones son meras reacciones de frustración: "en lugar de una práctica política concreta, tenemos una explosión estética violenta" (Žižek, 2004, p. 73), lo cual sería lo contrario de la organización de los soviets promovida por Lenin. Por ello, Žižek indica que

el Estado 'paranoico' que 'reterritorializa' la explosión esquizofrénica de la multitud molecular no es el único marco imaginable de la organización social colectiva global; el partido revolucionario leninista da cuerpo (o, más bien, anuncia) una lógica de colectividad totalmente distinta (Žižek, 2004, p. 74). ${ }^{14}$

En este sentido, la figura de Lenin puede significar una alternativa que ayude a superar el dilema entre el autogobierno de la multitud y el representante que le impone violentamente un gobierno. La cuestión es si Lenin, en efecto, fue una diferencia entre el aprovechamiento revolucionario del instante y su degradación totalitaria.

Para Žižek, una interpretación del fin del periodo revolucionario ruso, alternativa a la de Castoriadis, ${ }^{15}$ es que se agotó a finales de la década de los veinte cuando la colectivización y la industrialización llegaron a su límite (Žižek, 2006, p. 233). El potencial del leninismo, desde esta perspectiva, más allá de las dificultades de la Nueva Política Económica, tendría que apreciarse en el gran impulso hacia delante de 1928 a 1933, donde se dio una transformación radical del cuerpo social ruso guiada por un Estado que seguía aún vinculado a su origen revolucionario. Después de ese periodo, lo que se impuso, bajo la influencia avasalladora del estalinismo, fue el nacionalismo ruso y el imaginario del realismo socialista.

¿Cuándo, entonces, se pasa del impulso de la violencia redentora a la violencia mítica? No basta con decir que la frustración del fracaso de las formas de organización social alimenta la violencia de los regímenes; algo sucede con el estatus simbólico de la violencia que la vuelve cualitativamente distinta a la revolucionaria. Para explicar esto, Žižek se ubica en la época que separa a Lenin de Stalin: "en tiempos de Stalin, el status simbólico del terror cambió por completo: el terror se convirtió en un suplemento tenebroso y obsceno, no reconocido públicamente, del discurso público oficial" (Žižek, 2004, p. 77). De una violencia reconocida públicamente y asumida por los ciudadanos, pasamos a un ejercicio secreto que sostiene el poder oficial.

14 Los conceptos de reterritorialización y esquizofrenia refieren a los desarrollos de Deleuze y Guattari (2010) en Capitalismo y esquizofrenia. Žižek muestra que el partido leninista ofrece una alternativa diferente a la de una multitud que actúa anárquicamente y un Estado que busca controlarla.

15 La cual coincide con la de Alain Badiou y Sylvain Lazarus (Žižek, 2006, p. 233). Por otro lado, para una confrontación del pensamiento de Castoriadis con el de Badiou respecto al concepto de política, el cual sigue motivaciones análogas a nuestro intento de poner en diálogo a Castoriadis con Zizek, consúltese Karavitis (2018). 
Para caracterizar esta mutación, Žižek (2004) introduce la noción de "violencia simbólica" (p. 79), como aquello que determina el marco de las elecciones y en función de lo cual se realiza en último término la lucha política. ${ }^{16}$ El revolucionario no simplemente lucha por la toma de decisiones, sino por reestructurar el marco en el que estas se toman. Un Estado como el estalinista clausura tal posibilidad, imponiendo un orden que oculta los antagonismos resultantes a través de una violencia efectiva pero no reconocida públicamente. En consecuencia, piensa Žižek, debería enfatizarse que, en el horizonte político, siempre habrá excluidos, los cuales deberían ser reconocidos como posibles agentes de cambio.

El punto a destacar es que no puede determinarse a priori ni la forma ni los lugares en que se darán las confrontaciones. Cualquier excluido puede reclamar su derecho como agente político y promover una revolución, en función de dos factores: las necesidades no consideradas por las formas de organización y la ambición de establecer una forma nueva. En este sentido, la teoría política tradicional que privilegia la reflexión sobre las formas de gobierno obstaculiza la comprensión de la revolución y su particular forma de violencia. Por ello, Žižek (2004, p. 82) se opone explícitamente a la separación de los ámbitos de lo político y lo social -característica de conceptualizaciones como la de Hannah Arendt (1967)-, como si las necesidades y los intereses económicos no pudieran de hecho jugar un rol en la conformación de la organización política.

Ahora bien, la actitud contraria -que Žižek denomina pospolítica-, ${ }^{17}$ en la que se rechaza cualquier forma de organización que pretenda representar y dirimir los antagonismos sociales, sustituyéndola por sistemas de gestión y formas de resistencia dispersas -lo cual parece coincidir justo con la dinámica capitalista-, implica para Žižek el problema de que estos no pueden relacionarse con la totalidad social. La lógica revolucionaria se debería ubicar, más bien, entre los dos polos, lo que le permite identificar las oportunidades de cambio y abarcar lo social en su totalidad.

En un sentido lacaniano, lo que se juega en estas distinciones entre la multitud y la representación totalizadora es la consistencia del orden simbólico. Y el problema al que nos enfrenta la revolución es el de qué quedará en su lugar si se desintegra. Nos enfrentamos, pues, al problema clásico de la legitimación del poder, el cual presenta complicaciones especiales en el caso de la revolución, porque "la única legitimación de una revolución es negativa, una voluntad de romper con el pasado" (Žižek, 2004, p. 135). ¿A qué puede aferrase entonces el revolucionario como esperanza para un futuro? "Para ocultar el hecho de que más allá no hay nada, el revolucionario tiene que aferrase (...) a la violencia como el único índice de autenticidad" (Žižek, 2004, p. 136). Žižek se esfuerza por distinguir la violencia revolucionaria de la totalitaria, destacando que el

\footnotetext{
16 Žižek, en Sobre la violencia (2009), muestra al detalle cómo diferentes tipos de violencia son ejercidos en relación al marco simbólico que los determina, lo cual exige considerar no sólo su análisis objetivo, sino la posición del sujeto.

17 Sobre lo pospolítico, consúltese Rancière (1996).
} 
revolucionario siente una especie de fascinación por el conflicto, a la que denomina pasión por lo Real, la cual se traduce en términos políticos en la toma de partido por la multitud que ha quedado excluida y sin representación; la "parte sin parte" (Žižek, 2004, p. 137) que, en tanto singular universal, "representa la 'pura' diferencia en cuanto tal, lo no social dentro del campo de lo social" (Žižek, 2004, p. 139).

El problema de esta forma de representación, que Žižek denomina política de la sustracción (2004, p. 139), es -como ya hemos establecido con Castoriadis- cómo puede instituirse tras el rompimiento con el sistema imperante. En tanto que el revolucionario busca ejercer el poder en nombre de quien se ubica más allá de cualquier delimitación política, carece de cualificaciones para determinar cómo representarlo. El lugar del poder permanece vacío. Y la cuestión sigue siendo en dónde podría encontrar el cuerpo social representaciones que le permitan organizarse efectivamente más allá del imaginario de la economía capitalista.

\section{Repetir el comienzo francés: Robespierre, el terror de la virtud}

Es aquí donde la figura de Robespierre se vuelve relevante. Convencionalmente, Maximilien Robespierre es asociado con la implantación del terror tras la Revolución francesa, y Žižek lo confirma, apuntando que fue movido por una pasión por lo Real que le permitió llevar hasta el final sus ideales, en un intento de reestructurar los principios del imaginario social moderno para efectivamente realizar sus ideales de libertad e igualdad. Lo que le importa destacar a Žižek es que la asunción de tal pasión en la forma de una política emancipadora sólo puede realizarse de forma terrorista. Por ello, el terror no puede simplemente condenarse y rechazarse, pues implica cierta virtud.

Robespierre mismo lo declara en la siguiente cita:

Si el principal instrumento del Gobierno popular en tiempos de paz es la virtud, en momentos de revolución debe ser a la vez la virtud y el terror: la virtud, sin la cual el terror es funesto; el terror, sin el cual la virtud es impotente. El terror no es otra cosa que la justicia rápida, severa e inflexible; emana, por lo tanto, de la virtud; no es tanto un principio específico como una consecuencia del principio general de la democracia, aplicado a las necesidades más acuciantes de la patria (Robespierre citado en Žižek, 2010, p. 7).

El terror, en esta representación, es lo que permite realizar de manera concreta la justicia, sacando a la virtud de su impotencia. El punto de Žižek es que, para evitar la corrupción de la revolución, el terror no debe dejar de depender de la virtud. Es crucial destacar que, "para Robespierre, el terror revolucionario es lo más opuesto a la guerra" (Žižek, 2010, p. 8). Como ya hemos mencionado, la violencia que un revolucionario considera necesaria no es una que, siguiendo la distinción de Benjamin (2001), pretenda fundar y defender un sistema legal que controle los medios e imponga los fines, sino un caso 
de violencia divina. Ahora bien, si Robespierre no buscaba fundar un Estado a través de la violencia, como Castoriadis y tantos otros le reprochan, ¿cómo pretendía realizar la justicia a través del terror? ¿Qué implica su violencia divina? Lo que Žižek establece es que, en Robespierre, violencia, justicia y soberanía permanecen esencialmente vinculados, lo cual impide el uso indiscriminado de la violencia, pues no sólo asume la responsabilidad de un acto totalmente libre, sino que exige que responda a una demanda social de justicia. ${ }^{18} \mathrm{Y}$, sin embargo, tal violencia no puede idealizarse porque la aplicación concreta sigue siendo el terror: “¿nos obliga la realidad (a menudo deplorable) del terror revolucionario a rechazar la propia idea del terror, o existe una forma de repetirlo en la actual configuración histórica, tan diferente, redimiendo el contenido virtual de su realización?" (Žižek, 2010, p. 13).

Žižek aboga por conservar cierta forma de violencia, pero matizándola: "la fórmula más concisa para repetir el acontecimiento designado como 'Robespierre' es pasar del terror humanista (robespierriano) al terror antihumanista (o más bien inhumano)" (Žižek, 2010, p. 13). Este terror inhumano, en oposición a la violencia ejercida por la multitud fuera de la ley, ha de entenderse como una especie de crueldad, de resonancias lacanianas, en la que el sujeto afronta el vacío que, en último término, da forma a su deseo de emancipación y justicia, asumiendo el peligro que implica llevarlo hasta sus últimas consecuencias, lo cual, en principio, le permitiría ser auténticamente radical, sin perder la estructura de la representación que totaliza su acción en una forma de acción política y colectiva consistente. ${ }^{19}$

Ahora bien, Žižek insiste en que esta crueldad inhumana debe pensarse vinculada a la ambición de organizar la soberanía manifestada en la revolución a través de una estructura estatal, pues el verdadero peligro de renunciar a la representación es el de caer en la pospolítica, dejando el tema de la organización en manos de expertos que supuestamente saben lo que es mejor, ${ }^{20}$ lo cual es uno de los rasgos característicos de la forma de organización dominada por el imaginario capitalista. Al respecto, Žižek propone conceptualizar la soberanía del pueblo como un exceso: "el exceso de la representación del Estado sobre lo que representa” (Žižek, 2010, p. 34). El revolucionario debería reconocer el exceso como una forma de violencia constitutiva de su propia posición, la cual, por ello, no puede representar todos los intereses, poniéndolo en la situación de tener que determinar por sí mismo cuáles serán representados, en un gesto dictatorial:

18 En este sentido, para Žižek (2009, p. 238), es Danton y no Robespierre quien representa la degeneración de la violencia divina en mítica, al justificar su utilización con fines de imposición de orden por parte del Estado.

19 Uno de los textos clave para comprender esta noción de crueldad es Kant con Sade (Lacan, 2009). (Žižek, 1998) ha reflexionado al respecto, demostrando que la intención de Lacan no es establecer que la verdad de la ética kantiana es la crueldad del sádico, sino que la verdad con la que el perverso intenta lidiar a través de sus escenificaciones es la crueldad del imperativo categórico que, en su rigor, no ofrece indicaciones sobre cómo obrar, responsabilizándonos de nuestra libertad.

20 Lo cual remite a la noción de "sujeto supuesto saber", que Lacan (1992) relaciona con los cuatro discursos (el del Amo, la Universidad, el Histérico y el Analista). En términos políticos, un revolucionario que actúa bajo la suposición de la existencia de tal sujeto, como Lacan reprochaba a los estudiantes en 1968, no busca responsabilizarse del ejercicio del poder, sino sustituir un amo por otro. 
Habría por tanto que desmitificar a fondo el espantajo de la 'dictadura del proletariado': lo que representa fundamentalmente es el momento trémulo en que la compleja red de representaciones queda suspendida debido a la intrusión directa de la universalidad en el campo político (Žižek, 2010, p. 36).

Lo que en último término representaría un revolucionario en el poder no es el ideal del pueblo emancipado, sino el vacío dejado por la intrusión de la soberanía en el acto revolucionario -en esto consiste el terror que representa Robespierre: el enfrentamiento con la inconsistencia del orden simbólico-, en un intento de reparar la coherencia de la estructura que da forma política a la organización social, manteniendo en tensión "el cuerpo social estructurado, en el que cada parte tiene su lugar, y la 'parte sin ninguna parte' que sacude ese orden en nombre del principio vacío de universalidad" (Žižek, 2010, pp. 36-37). La dictadura que impone el revolucionario, paradójicamente, se erige en representación de la explosión democrática del pueblo, evitando la clausura ideológica del sistema, al mantener la tensión entre el orden social y el lugar de los sin-lugar, es decir, entre igualdad y exclusión.

En principio, la dictadura posibilitaría una democracia estructurada alrededor del Estado porque "admite la lucha antagónica como objetivo" (Žižek, 2010, p. 39), con procedimientos regulados, mientras que "el fascismo, por el contrario, trata de imponer el objetivo de la armonía jerárquicamente estructurada mediante un antagonismo desbocado" (Žižek, 2010, p. 39). En resumen, el problema se puede enunciar de la siguiente forma: “¿cómo regular/institucionalizar el violento impulso democráticoigualitario, cómo evitar que se vea sofocado en la democracia por el segundo sentido del término (procedimiento regulado)?" (Žižek, 2010, p. 40). Lo cual, a su vez, debe evitar la tentación de proclamar que "el pueblo existe" (Žižek, 2010, p. 41), como si fuera "una encarnación fenoménica directa del pueblo nouménico" (Žižek, 2010, p. 41).

Ciertamente, Žižek nos recuerda que una revolución es un acontecimiento en que lo nouménico se manifiesta en coincidencia con lo fenoménico -en referencia a las reflexiones de Foucault (2009, p. 17) sobre la Ilustración y la revolución-, como si la libertad adquiriera cuerpo en las masas inconformes. La tentación, sin embargo, es la de justificar el nuevo orden en función de necesidades objetivas, programas sociales o diseños económicos, como hicieron Danton y Stalin. El revolucionario debería aceptar la soberanía del acto que lo llevó al poder y responsabilizarse de ello en un gesto voluntarista de toma de postura incondicional que, por esto mismo, es plenamente ética.

\section{Conclusión: la violencia de la libertad}

Tras el análisis, hemos de destacar que en la transformación de la sociedad se nos impone el problema de la irrupción de la libertad, que nos enfrenta a la oportunidad de instituir un nuevo orden, pero también al riesgo de un orden más represivo y sin 
certeza económica. Al respecto, Žižek muestra que tal impulso se manifiesta sin ninguna forma de certeza, lo cual complica el reto de construir un imaginario alternativo, que en nuestra época se opondría al del capitalismo.

Ahora bien, aunque el revolucionario no cuenta con una metodología de reingeniería social, sí tiene como fundamento un fuerte compromiso subjetivo. En este sentido, Žižek piensa que la ambigüedad de los vínculos con la tradición y sus formas de autoridad exponen a cualquier revolución a una violencia que no tiene que ser necesariamente condenada, pues es su índice de autenticidad, como verdad que determina la posición del sujeto.

Ciertamente, tal violencia no está ausente de las consideraciones de pensadores como Castoriadis, pues reconoce en la ruptura un momento clave de la transformación social. Empero, piensa que no debe considerársele la esencia de la revolución, ya que ésta sólo culmina con la autoinstitución de la sociedad, como la realización de su libertad colectiva.

Para Žižek, sin embargo, el acto de institución no está libre de terror e incluso implica una violencia dictatorial que denomina simbólica o mítica. El problema, entonces, no se reduce al establecimiento de leyes, como si con ello se garantizara la libertad y el goce de la vida pública, sino que debe plantearse en términos del dilema que se les presentó tanto a Robespierre como a Lenin: cómo representar las aspiraciones de la multitud, a pesar de que se les tenga que excluir.

En este sentido, la revolución no puede reducirse a las decisiones de la multitud en el establecimiento de sus intereses, sino que ha de basarse en el reconocimiento de la soberanía del pueblo como el exceso de libertad que deja un vacío imposible de llenar. La representación de este vacío, como la conservación del elemento excluido, sería la indicación de su origen y vocación revolucionaria, de manera que, más que fomentar la participación ciudadana, favorece la expresión de demandas y posibilita la lucha por transformar las condiciones en que se ejerce el poder, a través de irrupciones que pueden ser violentas, pero también redentoras.

A su vez, esta noción de violencia implica un vínculo con la moralidad. Lo que valida el acto revolucionario no son sus consecuencias, sino el compromiso incondicional de las personas que lo asumen. Esta actitud es, para Žižek, propia del deber kantiano que un revolucionario encarna al dejar de actuar en función del cálculo de consecuencias, ${ }^{21}$ impulsado por "una confianza fundamental en la estructura favorable de la realidad"' (2005, p. 80).

En consecuencia, un revolucionario no intenta realizar lo que imagina como sociedad, porque eso sería responder a su fantasía y no al compromiso, ${ }^{22}$ lo cual provocaría, más que una violencia revolucionaria, una degradante..$^{23} \mathrm{El}$ acto revolucionario está

21 Una revolución "calculada" más bien correspondería a una ética utilitarista, lo cual se opone a la postura kantiana asumida por Žižek.

22 En particular, esto opone a Žižek contra cualquier forma de socialismo utópico. Al respecto, recuérdese la indicación de Žižek de que lo auténticamente utópico no radica en lo que la sociedad será después de la revolución, sino en el impulso revolucionario mismo, que Žižek ejemplifica con Lenin.

23 Es decir, aunque el deseo del revolucionario pueda sostenerse en la fantasía de un futuro mejor, su efectiva realización en la realidad 
directamente relacionado con el ejercicio de la libertad en la fundamentación moral de nuestras acciones, en el sentido de que traza una línea de separación entre lo nouménico y lo fenoménico. Lo que libera el imaginario es dejar de depender de las circunstancias impuestas por los sistemas en que predominan diversas formas de explotación y desigualdad. Esta separación es necesariamente violenta, pero no deplorable, porque funciona como condición del ejercicio de la libertad.

Por supuesto, la revolución debe aspirar a garantizar la libertad a través de instituciones. Pero esto implica, más que la autogestión del colectivo, la posibilidad de hacer públicos los antagonismos sociales, lo cual se opone a la violencia fascista que se esfuerza en ocultarlos.

El imaginario social revolucionario implicaría, así, una constante tensión entre destrucción y creación; ruptura ocasionada por la irrupción de la libertad del colectivo e institucionalización a través de una forma de representación de esa libertad, que podría llegar a adquirir un valor propio e independiente de las demandas colectivas, como sucede en los procesos de valorización capitalistas. “¿No es esto la fórmula exacta del vínculo entre pulsión de muerte y sublimación?" (Žižek, 2006, p. 240).

\section{Referencias}

Adorno, T. \& Horkheimer, M. (2002). Dialectic of the Enlightenment. California: Stanford University Press.

Althusser, L. (2008). Lenin y la filosofía. En La soledad de Maquiavelo (C. P. del Campo \& R. Sánchez Cedillo, Trads.). Madrid: Akal.

Álvarez, A. R. (2013). El acto fantasmal: repercusiones políticas del concepto de acontecimiento en la obra de Slavoj Žižek. Contrastes, 1(18), 159-178. https://doi.org/10.24310/Contrastescontrastes.v18i1.1222

Arendt, H. (1967). Sobre la revolución (P. Bravo, Trad.). Madrid: Revista de Occidente.

Badiou, A. (2003). El ser y el acontecimiento. Buenos Aires: Manantial.

Badiou, A. (2008). Lógica de los mundos. Buenos Aires: Manantial.

Badiou, A. (2018). L'Immanence des vérités. Paris: Fayard.

Badiou, A., et. al. (2010). Sobre la idea del comunismo (A. Hounie, Comp.). Buenos Aires: Paidós.

Bataille, G. (1987). La parte maldita. Barcelona: Editorial Icaria.

Benjamin, W. (2001). Para una crítica de la violencia. En Para una crítica de la violencia y otros ensayos. Iluminaciones 4 (pp. 23-46). Madrid: Taurus.

social terminaría humillándolo, porque ridiculizaría lo que en su estructura subjetiva no era más un anhelo de reconciliación que le servía de sostén. De realizarse, el anhelo y el sostén psíquico que ofrecía, se perderían. 
Benjamin, W. (2003). La obra de arte en la época de su reproductibilidad técnica. México: Ítaca. Benjamin, W. (2004). El autor como productor. México: Ítaca.

Butler, J. (2006). Critique, Coercion, and Sacred Life in Benjamin's 'Critique of Violence'. En Political Theologies: Public Religions in a Post-secular World (pp. 201-219). New York: Fordham University Press. https://doi.org/10.5422/fso/9780823226443.003.0009

Camargo, R. (2013). Rethinking the Political: A Genealogy of the 'Antagonism' in Carl Schmitt through the Lens of Laclau-Mouffe-Žižek. New Centennial Review, 1(13), 161-188. https://doi.org/10.1353/ncr.2013.0003

Castoriadis, C. (1991). ¿La idea de revolución tiene sentido todavía? Estudios, 24, 7-25. (Tomado de Castoriadis, C. (1990). Le monde morcelé, les carrefours du laberynthe 3. Paris: Seuil. https://doi.org/10.5347/01856383.0024.000170708

Critchley, S. (2009). Violent Thoughts About Slavoj Žižek. Naked Punch, 11, 3-6. http://www.nakedpunch.com/articles/39

Deleuze, G. \& Guattari, F. (2010). Mil mesetas: capitalismo y esquizofrenia. Valencia: Pre-textos.

Foucault, M. (2009). El gobierno de sí y de los otros. México: FCE.

Heidegger, M. (2001). Introducción a la metafísica. Barcelona: Gedisa.

Hernández Vergara, E. (2018). Žižek, la rehabilitación de la política de la verdad y la ideología. Logos. Revista de Filosofía, Postmodernism, 131(46), 77-104. https://doi.org/10.26457//rf.v0i131.1752

Jameson, F. (1991). Postmodernism or, the Cultural Logic of Late Capitalism. London: Verso. https://doi.org/10.1215/9780822378419

Karavitis, G. (2018). On the concept of politics: A comparative reading of Castoriadis and Badiou. Constellations. An International Journal of Critical and Democratic Theory, 25(2), 256271. https://doi.org/10.1111/1467-8675.12339

Lacan, J. (1992). El seminario 17. El reverso del psicoanálisis. Barcelona: Paidós.

Lacan, J. (2009). Kant con Sade. En Escritos 2. México: Siglo Veintiuno Editores.

Lukács, G. (2005). Lenin. Estudio sobre la coherencia de su pensamiento. Buenos Aires: Gorla. Marx, K. (1974). Tesis sobre Feuerbach. En La ideología alemana (W. Roces, Trad.). Barcelona: Grijalbo. Moreno Pestaña, J. L. (2018). Sobre la democracia antigua como problema filosófico en Foucault, Castoriadis y Rancière. Logos. Anales del Seminario de Metafísica. 51, 139-156. https://doi.org/10.5209/ASEM.61647

Ponce L. (2020). De Rosa Luxemburgo a Cornelius Castoriadis. Entre el socialismo y la caída en la barbarie. Las Torres de Lucca. Revista Internacional de Filosofía Política, 9(16), 109-133. http://www.lastorresdelucca.org/index.php/ojs/article/view/355

Rancière, J. (1996). El desacuerdo (H. Pons, Trad.). Buenos Aires: Nueva Visión.

Ricœur, P. (1986). Lectures on Ideology and Utopia. New York: Columbia University Press.

Rosso, G. (2020). De la clase revolucionaria a la subjetividad humana. Sobre el sujeto de la autonomía en la obra de Cornelius Castoriadis. Las Torres 
de Lucca. Revista Internacional de Filosofía Política, 9(16), 135-157. http://www.lastorresdelucca.org/index.php/ojs/article/view/356

Telios, T. (2019). Resisting the Creativity Narrative: Cornelius Castoriadis on the Fundaments of Capitalist Subjectivity. Symposium: Canadian Journal of Continental Philosophy, 23(1), 31-55. https://doi.org/10.5840/symposium20192313

Wennerscheid, S. (2014). The Passage through Negativity, or from Self-renunciation to Revolution? Kierkegaard and Žižek on the Politics of the Impassioned Individual. In Kierkegaard and Political Theory: Religion, Aesthetics, Politics and the Intervention of the Single Individual (pp. 140-165). Copenhagen: Museum Tusculanum Press.

Žižek, S. (1998). Kant and Sade: The Ideal Couple. Lacanian Ink, 13. http://www.lacan.com/zizlacan4.htm

Žižek, S. (2001). La política de la verdad, o Alain Badiou como lector de San Pablo. En El espinoso sujeto. El centro ausente de la ontología política (pp. 137-181). Buenos Aires: Paidós.

Žižek, S. (2004). Repetir a Lenin: trece tentativas sobre Lenin (M. Malo de Molina \& R. Sánchez Cedillo, Trads.). Madrid: Akal.

Žižek, S. (2006). Órganos sin cuerpo. Sobre Deleuze y consecuencias (A. G. Cuspinera, Trad.). Valencia: Pre-Textos.

Žižek, S. (2009). Sobre la violencia. Seis reflexiones marginales. Buenos Aires: Paidós.

Žižek, S. (2010). Robespierre, o la 'violencia divina' del terror. En Virtud y terror. Slavoj Žižek presenta a Robespierre (pp. 5-51). Madrid: Akal.

Žižek, S. (2013). Demanding the impossible. Cambridge: Polity Press. 